This is a self-archived - parallel published version of this article in the publication archive of the University of Vaasa. It might differ from the original.

\title{
IoT-Enabled Operation of Multi Energy Hubs Considering Electric Vehicles and Demand Response
}

Author(s): Kazemi, Behzad; Kavousi-Fard, Abdollah; Dabbaghjamanesh, Morteza; Karimi, Mazaher

Title: IoT-Enabled Operation of Multi Energy Hubs Considering Electric Vehicles and Demand Response

Year: $\quad 2022$

Version: Accepted version

Copyright (C) 2022 IEEE. Personal use of this material is permitted. Permission from IEEE must be obtained for all other uses, in any current or future media, including reprinting/republishing this material for advertising or promotional purposes, creating new collective works, for resale or redistribution to servers or lists, or reuse of any copyrighted component of this work in other works.

\section{Please cite the original version:}

Kazemi, B., Kavousi-Fard, A., Dabbaghjamanesh, M. \& Karimi, M. (2022). IoT-Enabled Operation of Multi Energy Hubs Considering Electric Vehicles and Demand Response. IEEE Transactions on Intelligent Transportation Systems, 1-9. https://doi.org/10.1109/TITS.2022.3140596 


\title{
IoT-Enabled Operation of Multi Energy Hubs Considering Electric Vehicles and Demand Response
}

\author{
Behzad Kazemi, Abdollah Kavousi-Fard, Morteza Dabbaghjamanesh, Mazaher Karimi
}

\begin{abstract}
This paper introduces a novel Internet of Thing (IoT) enabled approach for optimizing the operation costs and enhancing the network reliability incorporating the uncertainty effects and energy management in multi-carrier Energy Hub (EH) and integrated energy systems (IES) with renewable resources, Combined Heat and Power (CHP) and Plug-In Hybrid Electric Vehicle (PHEV). In the proposed model, the optimization process of different carriers of Multi Energy Hubs (MEH) energy considers a price-based demand response (DR) program with MEH electrical and thermal demands. During the peak period, energy carrier prices are calculated at high tariffs, and other power hubs can help to reduce hub energy costs. The proposed model can handle the random behavior of renewable sources in a correlated environment and find optimal solution for turbines' communication in EHs. The simulation results show the high performance of the proposed model by considering the dependency between wind turbines in MEH structure, power exchange and heat among the EHs.
\end{abstract}

Keywords: Multi Energy Hub, IoT, Unscented Transform.

Nomenclature
Parameters
$p_{i / m_{j}}$
$H_{H S}^{\text {initial }}$
$\alpha_{H S}^{\text {charge }}$
$\alpha_{H S}^{\text {Discharge }}$
$P_{H S, \text { ch }}^{\text {max }} /$
$P_{H S, \text { dch }}^{\text {max }}$
$H_{H S}^{\text {min }} / H_{H S}^{\text {max }}$
$P_{P H E V}^{\text {initial }}$
$\alpha_{P H E V}^{\text {charge }}$
$\alpha_{P H E V}^{\text {Discharge }}$
$P_{P H E V}^{\text {min }} /$
$P_{P H E V}^{\text {max }}$
$P_{P H E V, c h}^{\text {max }} /$
$P_{P H E V, \text { dch }}^{\text {max }}$
$\delta$
$\varepsilon$
$\mathrm{K}$
$\gamma$
$L P F_{\text {shdo/shup }}$
$P_{d e m a n d}^{t} /$
$H_{\text {demand }}^{t}$

\footnotetext{
${ }^{1}$ B Kazemi and A Kavousi-Fard are with the Electrical and Electronics Engineering Department, Shiraz University of Technology, Shiraz, Iran (behzadkazemi96@gmail.com, kavousi@sutech.ac.ir).
}

\begin{tabular}{|c|c|}
\hline $\begin{array}{l}\operatorname{shdo}_{D R}^{t} / \\
\operatorname{shup}_{D R}^{t}\end{array}$ & Binary Means for Down/Up of DR \\
\hline$\lambda_{N G_{s}}^{t} / \lambda_{E_{S}}^{t}$ & $\begin{array}{l}\text { Hourly Prices of Natural Gas and } \\
\text { Electricity in Time-Of-Operation }\end{array}$ \\
\hline$\lambda_{\text {Bat }_{S}}^{t} / \lambda_{H S_{S}}^{t}$ & $\begin{array}{l}\text { Hourly Prices of Battery and Heat } \\
\text { Storage in Time-Of-Operation }\end{array}$ \\
\hline$\lambda_{P H E V_{S}}^{t}$ & $\begin{array}{l}\text { Hourly Prices of PHEV Battery in } \\
\text { Time-Of-Operation }\end{array}$ \\
\hline$\lambda_{D R_{S}}^{t}$ & $\begin{array}{l}\text { Hourly Prices of Demand Response in } \\
\text { Time-Of-Operation }\end{array}$ \\
\hline$I_{s c}$ & Short Circuit Current of PV Modules \\
\hline$K_{\tau}$ & $\begin{array}{l}\text { Short Circuit Current Temperature } \\
\text { Coefficient }\end{array}$ \\
\hline$K_{\rho \beta}$ & Max Temperature Coefficient Capacity \\
\hline$K_{\iota}$ & $\begin{array}{l}\text { Open Circuit Voltage Temperature } \\
\text { Coefficient }\end{array}$ \\
\hline$T_{O P}$ & $\begin{array}{l}\text { Normal Operating Temperature Of PV } \\
\text { Modules }\left({ }^{\circ} \mathrm{C}\right)\end{array}$ \\
\hline $\mathrm{W}$ & Weight coefficient \\
\hline$P_{o u t}$ pv & Rated Capacity of PV Module \\
\hline$P_{v T C}$ & $\begin{array}{l}\text { PVAs Module Electrical Rated } \\
\text { Capacity at Standard Test Conditions }\end{array}$ \\
\hline $\mathrm{m}$ & Input random variable \\
\hline$P V_{a v}$ & $\begin{array}{l}\text { Rated Capacity of the PV at Solar } \\
\text { Radiation }\end{array}$ \\
\hline$v$ & Solar Radiation Level to the PV Module \\
\hline$G_{S}$ & $\begin{array}{l}\text { Solar Radiation Level on a Horizontal } \\
\text { Plane of State S }\end{array}$ \\
\hline$P_{Z Z}$ & Covariance of input variable \\
\hline$v_{v T C}$ & $\begin{array}{l}\text { Solar Irradiance at Standard Test } \\
\text { Conditions }\end{array}$ \\
\hline$T_{P V}^{c e l l}$ & Temperature of the PV Cell \\
\hline$T^{a m b}$ & Temperature of the Ambient \\
\hline $\begin{array}{l}\mathrm{I}_{M P P} \\
\text { Variables }\end{array}$ & Max Power Spot Current (A) \\
\hline$P_{C H P}^{t}$ & Power Produced By CHP at $t$ \\
\hline$H_{C H P}^{t}$ & Heat Produced By CHP at $t$ \\
\hline$\sigma_{t}^{t} / \vartheta_{j}^{t}$ & $\begin{array}{l}\text { Sections of Electrical/Heat Produced Of } \\
\text { CHP }\end{array}$ \\
\hline$H_{H S}^{t}$ & Stored Heat Energy in Storage Unit \\
\hline$P_{C H_{H S}}^{t}$ & $\begin{array}{l}\text { Upper Limits of Charge Power of Heat } \\
\text { Storage Unit }\end{array}$ \\
\hline$P_{D C H_{H S}}^{t}$ & $\begin{array}{l}\text { Upper Limits of Discharge Power of } \\
\text { Heat Storage Unit }\end{array}$ \\
\hline$P_{P H E V}^{t}$ & PHEV Battery Charge State at the End \\
\hline
\end{tabular}

M. Dabbaghjamanesh is with the Smart Power Tech LLC. Louisiana, USA. (dabaghmanesh.morteza@gmail.com)

M. Karimi is with the School of Technology and Innovations, University of Vaasa, Finland. (Mazaher.karimi@uwasa.fi) 


$P_{C H_{P H E V}}^{t} /$
$P_{D C H_{P H E V}}^{t}$
$P_{\text {shdo }}^{t} / P_{\text {shup }}^{t}$
$P_{E, N e t_{n}}^{t}$
$P_{G, \text { Net }}^{t}$
$P_{M T_{n}}$
$P_{\text {heat }}^{t}$
$P_{n}^{t}$ to $m$
$P_{P 2 G}^{t}$
$H_{C H P}^{t}$
$P_{C H_{B a t}}^{t}$
$P_{D C H_{B a t}}^{t}$
$P_{y}$
$H_{\text {heat }}^{t}$
$H_{n \text { to }}^{t}$
$H_{\text {shdo }}^{t} / H_{\text {shup }}^{t}$
$P_{\text {Boiler }}^{t}$
$H_{M T_{n}}$
$\Upsilon$

PHEV Charging /Discharging Energy

Shifted Up and Down Power by DR
Power Exchanged by the Main Grid
Amount of Cubic Meters of Natural Gas
Entering the Network
Power of Micro Turbine $n$
Power Used In Electric Heater
Power Exchanging Between Hub $n$ \& $m$
Rated Power Used In P2G
Rated Heat Produced By CHP
Upper Limits of Battery Charge Power
Upper Limits of battery Discharge
Power
Covariance of output variable
Rated Power Used In Electric Heater
Heat Exchanged Between Hub $n$ and $m$
Shifted Up and Down Heat by DR
Rated Power Produced By Boiler
Rated Heat Produced by Microturbine $n$
Mean value of output random variable

I. Introduction

Many definitions of energy hub (EH) have been proposed as an emerging concept in recent years. The existing literature provides valuable insights into the efficiency of energy systems. An EH is defined as a node in multi-carrier energy systems (MCES) in which energy can receive energy carriers at input ports and determine when much energy is stored and how to supply the basic needs of the energy hub [1][2][3]. Renewable energy programs, such as solar panels, wind turbine (WT), demand response (DR), energy storage (ES), and combined heat and power (CHP), improve the EH concept. Optimal exploitation of energy hubs in terms of economic, technical, and environmental benefits has led to the flexibility and stability of energy systems. Connecting multiple power hubs improves energy efficiency compared to the separate operation of hubs. In other words, when energy carriers are highly costly, other energy hubs can increase their capacity and reduce consumption costs [4].

Furthermore, the exchange of power and heat in EHs reduces operation costs, improves reliability, and ensures better balance. Renewable energy is an increasingly popular and practical technology. Given the random behavior of renewable sources, their output power is associated with uncertainty. Uncertainty studies adopt different models to address these uncertainties while exploring the output power of these resources. There are several common methods in modeling uncertainty, including the Monte Carlo method for generating different scenarios[5], the point estimation method[6], the scenario-based planning method[7]. Several studies have also used the definitive model to generate renewable resources[8]. The $\mathrm{EH}$ is another piece of equipment in energy storage. With the uncertainty of the output power of renewable resources, incorporating energy storage systems into network equipment is an effective solution for stabilizing energy fluctuations in renewable resources for loads requiring constant energy[9]. However, ESS is also used to adjust the load demand curve. When power and natural gas demand is off-peak, the energy is stored. The energy is released during peak hours to reduce network costs and improve network reliability[10]. Since solar energy is not generated at night, combined heat and power (CHP) systems are used to balance and supply different energy demands more efficiently. In addition to generating electricity, CHP units use extra heat to minimize costs[11-13]. Converting power to gas (P2G) reduces the cost of operating EHs and the interdependence between natural gas and electricity networks to ensure the more efficient operation of the natural gas network [14-17].

Previous research is consistently silent optimal simultaneous relationship between several hubs in multi-carrier energy systems (MCESs). Likewise, price-based DR programs, which reduce costs by exchanging power and heat between commercial, industrial, and residential hubs, have rarely been addressed in previous studies. This paper proposes a robust optimization model for the optimal performance of multiple EHs and the random behavior of renewable resources based on the unscented transformation (UT) uncertainty method to fill this gap. The main contributions of this study are as follows: I) It proposes an IoT-enabled optimal operating model for energy management among three EHs to reduce operating costs and enhance network reliability and II) It develops a UT-based stochastic framework for the uncertainty modeling of renewable resources in a correlated environment. III) It introduces a UT-based plan to control severe renewable energy resource fluctuations, making the proposed model less computationally demanding and more efficient. Also, the proposed model considers the dependence between wind turbines.

\section{Overview of Proposed IoT-Enabled MEH}

The proposed IoT-enabled MEH system consists of three interconnected residential, commercial, and industrial energy hubs. It uses the IoT for among different energy hubs [18-21]. Each EH consists of CHP, clean renewables, PHEV, boiler, heat storage (HS) units, and similar components. The EHs rely on natural gas and electricity as the main sources of power. The IoT technology provides the required situation for real-time data transferring based on sensors and secured communication channels. One point is to consider the requirements for the IoT assets based on power consumption and durability and small form factor which can help much in EHs. Through the IoT, higher observability would be achieved with very low latency in data communication.

\section{A. The operational and practical limitations of CHPs}

As a power-generating technology, a CHP system receives natural gas input and simultaneously uses heat and electricity to supply the required loads. CHPs consist of power-only, combined heat and power (cogeneration), and heat-only units. Cogeneration reduces energy consumption and greenhouse gas emissions. In this paper, a production-based CHP unit has been used. A polygon represents the operating points of four CHPs in Fig. 1. Power and heat in a CHP cannot be controlled separately since they are interdependent. Eqs. 1-5 show the fuel consumption of the CHP[22].

$$
\begin{aligned}
G_{i n}^{t} & =A_{0}+\sum_{i=1}^{I} p_{i} \sigma_{i}^{t}+\sum_{j=1}^{J} m_{j} \vartheta_{j}^{t} \\
P^{t} & =E b^{0}+\sum_{i=1}^{I} \sigma_{i}^{t}
\end{aligned}
$$




$$
\begin{aligned}
& H^{t}=\sum_{j=1}^{J} \vartheta_{j}^{t} \\
& 0 \leq \sigma_{i}^{t} \leq\left(E b^{i}-E b^{i-1}\right) \\
& 0 \leq \vartheta_{j}^{t} \leq\left(H b^{j}-H b^{j-1}\right)
\end{aligned}
$$

Fig. 1 shows the possible operating area for the CHP unit. The order of the area below the $A B$ curve, the area under the $B C$ curve, and the top surface of the $C D$ curve are represented in Eqs. 6-8. Fig. 1 shows the possible operation area for unit $C$.

$$
\begin{aligned}
& E_{C H P, O P}^{t}-E_{C H P, O P}^{A}-\frac{E_{C H P, O P}^{A}-E_{C H P, O P}^{B}}{H_{C H P, O H}^{A}-H_{C H P, O H}^{B}}\left(H_{C H P, O H}^{t}-H_{C H P, O H}^{A}\right) \leq 0 \\
& E_{C H P, O P}^{t}-E_{C H P, O P}^{B}-\frac{E_{C H P, O P}^{B}-E_{C H P, O P}^{C}}{H_{C H P, O H}^{B}-H_{C H P, O H}^{C}}\left(H_{C H P, O H}^{t}-H_{C H P, O H}^{B}\right) \geq 0 \\
& E_{C H P, O P}^{t}-E_{C H P, O P}^{C}-\frac{E_{C H P, O P}^{C}-E_{C H P, O P}^{D}}{H_{C H P, O H}^{C}-H_{C H P, O H}^{D}}\left(H_{C H P, O H}^{t}-H_{C H P, O H}^{C}\right) \geq 0
\end{aligned}
$$

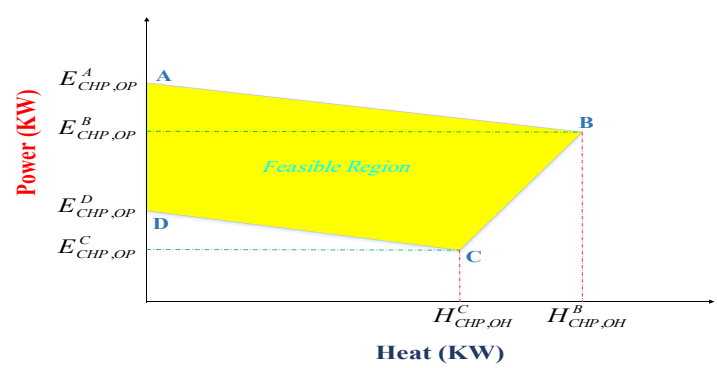

Fig 1. The feasible operational area for the CHP unit.

\section{B. Energy storage unit}

Energy storage unit (ESU) or energy storage unit is a useful technology for storing energy to be used during demand peaks. ESUs improve network reliably and prevent critical events. This paper uses the storage of heat and battery energy as follows:

B.1. Heat storage system: The thermal energy generated by CHPs and boilers is stored at off-peak hours. It is available to thermal loads in the peak hours during which the energy carrier is calculated at high tariffs. The mathematical equations of the heat storage unit is expressed as [23]:

$$
\begin{aligned}
& H_{H S}^{t}=H_{H S}^{i n i t i a l}+\sum_{t=1}^{24}\left(\alpha_{H S}^{C h \text { arge }} P_{C H_{H S}}^{t}-\frac{P_{D C H_{H S}}^{t}}{\alpha_{H S}^{D i s c h \text { arge }}}\right) \\
& H_{H S}^{\min } \leq H_{H S}^{t} \leq H_{H S}^{\max } \\
& 0 \leq P_{C H_{H S}}^{t} \leq P_{H S, C H}^{\max } \cdot c h_{H S}^{t} \\
& 0 \leq P_{D C H_{H S}}^{t} \leq P_{H S, D C H}^{\max } \cdot d c h_{H S}^{t} \\
& 0 \leq c h_{H S}^{t}+d c h_{H S}^{t} \leq 1
\end{aligned}
$$

The amount of heat stored by HS per hour is shown by Eq. (9). The heat energy stored from HS must be between the maximum and minimum amount shown in Eq. (10). HS's maximum charge and discharge power are limited to Eqs. (11) and (12), respectively, to not exceed a certain extent. HS prevents both charging and discharging processes in Eq. (13).

\section{B.2. Power storage of battery}

The batteries can manage the energy network by storing electrical energy at off-hours, reducing purchasing power from the network and the associated cost. They consist of various types. Lithium-ion (LIBs) is one of the most important types of batteries. The mathematical equations of battery energy storage and the same thermal storage system are similar.

\section{B.2. Storage of battery power}

The batteries can manage the energy network by storing electrical energy at off-hours, reducing purchasing power from the network and the associated cost. They consist of various types. Lithium-ion (LIBs) is one of the most important types of batteries. The mathematical equations of battery energy storage are similar to the thermal storage system so it is not mentioned here.

\section{PHEV FLEETS}

PHEVs are connected to the system at intervals and thus may not be connected to the system within a certain timeframe. Assuming that it is not connected to the network in the time interval $[a, b]$, its mathematical equations will be [24]:

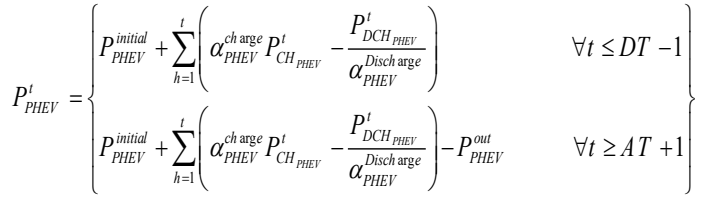

$$
\begin{aligned}
& P_{P H E V}^{\min } \leq P_{P H E V}^{t} \leq P_{P H E V}^{\max } \\
& P_{P H E V}^{t^{\prime}}=P_{P H E V}^{\text {initial }} \\
& P_{P H E V}^{D T-1}=P_{P H E V}^{\max } \\
& 0 \leq P_{C H_{P H E V}}^{t} \leq P_{P H E V, C H}^{\max } \cdot \operatorname{ch}_{P H E V}^{t} \\
& 0 \leq P_{D C H_{\text {PHEV }}}^{t} \leq P_{P H E V, D C H}^{\max } \cdot d c h_{P H E V}^{t} \\
& c h_{P H E V}^{t}+d c h_{P H E V}^{t} \leq 1
\end{aligned}
$$

Eq. (14) indicates the SOC of the PHEV battery during its connection hours. The SOC limit of the PHEV battery must be limited to a specific range, as shown in Eq. (15). Eq. (17) states that the PHEV battery should be fully charged before disconnection. The maximum charging and discharging capacity of the PHEV battery are limited to Eqs. (18) and (19), respectively, to avoid exceeding a certain limit. Finally, Eq. (20) states that the PHEV battery prevents both charging and discharging processes simultaneously.

\section{PV model}

Air pollution and greenhouse gases (GHG) are some of the most critical challenges modern societies have to deal with today. Solar panels are widely used by various industrial, residential, and commercial sectors to reduce $\mathrm{CO}_{2}$ discharge by converting light energy into electricity:

$$
\begin{aligned}
& T_{p v}^{c e l l}=T^{a m b}+G_{p v}\left(\frac{T_{O p}-20}{0.8}\right) \\
& l_{p v}=G_{p v}\left(I_{S C}+K_{\tau}\left(T_{p v}^{c e l l}-25\right)\right) \\
& V_{p v}=V_{o c}-K_{t} T^{c e l l} \\
& P V_{a p v}\left(G_{p v}\right)=N \cdot F_{F} V_{p v} \cdot I_{p v}
\end{aligned}
$$




$$
F_{F}=\frac{V_{M P P} I_{M P P}}{V_{o c} I_{s c}}
$$

Due to the unknown behavior of PV modules, the output power of these sources is unknown. Solar panels are associated with uncertainty, as their output power depends on daylight and is minimized at night. Here, the PDF of solar radiation has been used for modeling the uncertainty of PV's output power. The related equations are as follows[25]:

$$
f_{p v}(\nu)=\frac{1}{\delta \sqrt{2 \pi}} \exp \left(-\left(\frac{1}{2}\right)\left(\frac{(\nu-\varepsilon)}{\delta}\right)^{2}\right)
$$

Finally, the PV power, a function of ambient temperature and solar radiation, is obtained from Eq. (27)[26].

$$
P_{o u t_{p v}}=P_{v T C} \times \frac{v}{v_{v T C}} \times\left(1+K_{M P P T}\left(T^{\text {cell }}-T^{a m b}\right)\right)
$$

\section{E. Wind Energy Modeling}

Wind power rotates the turbines to generate electricity, reducing fossil fuel consumption and air pollution[27-28].

$$
\begin{array}{rlrl}
P_{\text {wind }}^{t}(\psi)=\left\{\begin{array}{lll}
P_{r}^{\text {wind }} & \text { if } & \psi_{r} \leq \psi^{t}<\psi_{\text {out }} \\
\frac{\psi^{t}-\psi_{\text {in }}}{\psi_{r}-\psi_{\text {in }}} p_{r}^{\text {wind }} & \text { if } & \psi_{\text {in }} \leq \psi^{t}<\psi_{n} \\
0 & \text { if } & \psi^{t}<\psi_{\text {in }}, \psi>\psi_{\text {out }}
\end{array}\right\} \\
f_{\text {wind }}(\nu)=\frac{k}{\gamma}\left(\frac{v}{\gamma}\right)^{k-1} \cdot e^{-\left(\frac{v}{\gamma}\right)^{k}} & \forall v \geq 0, \gamma>0, k>0
\end{array}
$$

\section{F. DR Program}

The mathematical equations of the DR program are as follows[29]:

$$
\begin{aligned}
& \sum_{t=1}^{24} P_{s h d}^{t}=\sum_{t=1}^{24} P_{s h u}^{t} \\
& 0 \leq P_{\text {shd }}^{t} \leq L P F_{\text {shd }} \cdot P_{\text {demand }}^{t} \cdot s h d_{D R}^{t} \\
& 0 \leq P_{\text {shu }}^{t} \leq L P F_{\text {shu }} \cdot P_{\text {demand }}^{t} \cdot s h u_{D R}^{t} \\
& \text { shd }{ }_{D R}^{t}+\text { shu }_{D R}^{t} \leq 1
\end{aligned}
$$

According to Eq. (30), the reduction in the total load by DR should equal the total increase in the load in 24 hours. The power decrease and increase should be limited to less than the specific percentage examined by Eqs. (31) and (32). Eq. (33) states that increasing or decreasing load cannot occur simultaneously in any time interval.

\section{G. Random framework based on UT technique}

In order to describe the uncertainty modeling by UT, we assumed that we have a stochastic nonlinear problem $A_{i}=$ $h\left(z_{i}\right)$, where $z_{i}$ is the input, $A_{i}$ represents stochastic variables output, and $h$ is a nonlinear function. Using $P_{z z}$ and the mean vector of the uncertainty variables $n, z_{i}=m$ is solved to calculate the weight coefficients assigned to each state based on Eqs. (37-39). The mean value and the covariance matrix of the relationship are achieved by Eqs. 4241 [30]:

$$
\begin{aligned}
& z_{0}=m \\
& z_{i}=m+\left(\sqrt{\frac{n}{1-W_{0}} P_{z z}}\right)_{i} ; i=1,2, \ldots, n \\
& z_{i}=m-\left(\sqrt{\frac{n}{1-W_{0}} P_{z z}}\right)_{i} ; i=1,2, \ldots, n
\end{aligned}
$$

With a constant initial value $W_{0}=0.25$, the weight coefficients are obtained by Eqs. 37-39 in the second step.

$W=W_{0}$

$$
\begin{aligned}
& W_{i}=\frac{1-W_{0}}{2 n} ; i=1,2, \ldots, n \\
& W_{i+n}=\frac{1-W_{0}}{2 n} ; i+n=n+1, \ldots, 2 n
\end{aligned}
$$

The sum of the weighting factors to the samples is equal to 1 .

$$
\sum_{i=0}^{2 n} W_{i}=1
$$

$A_{i}=h\left(z_{i}\right)$, is calculated for each vector point of output variables, and then by using the following equation, the mean value and $P_{y}$ covariance is calculated.

$$
\begin{aligned}
& \Upsilon=\sum_{i=0}^{2 n} W_{i} \mathrm{~A}_{i} \\
& P_{y}=\sum_{i=0}^{2 n} W_{i}\left(\mathrm{~A}_{i}-\Upsilon\right)\left(\mathrm{A}_{i}-\Upsilon\right)^{T}
\end{aligned}
$$

\section{III- Mathematical problem formulation}

\section{A. Objective function}

The performance of the proposed MEH objective function is to minimize the cost of the entire system over time, achieve maximum efficiency and increase system reliability.

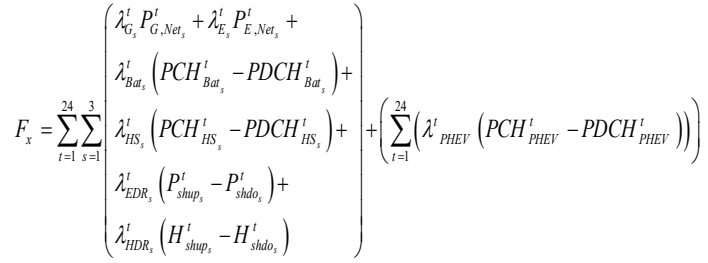

$$
\begin{aligned}
& P_{E, N e t}^{t}=P_{E, \mathrm{Net}_{1}}^{t}+P_{E, \mathrm{Net}_{2}}^{t}+P_{E, \mathrm{Net}_{3}}^{t} \\
& P_{G, N e t}^{t}=P_{G, N^{2} t_{1}}^{t}+P_{G, N_{N} t_{2}}^{t}+P_{G, N e t_{3}}^{t}
\end{aligned}
$$

Eq. (43) shows the unit energy price produced by the optimization problem. The energy costs of purchasing electricity and gas from the main network are expressed in the first and second terms. The third and fourth terms indicate the cost of charging and discharging batteries and energy storage. The DR program costs for thermal and electrical loads are the fifth and sixth terms. The final term refers to charging and discharging costs.

\section{B. Proposed MEH energy balance}

Electricity and heat balance in the proposed $\mathrm{MEH}$ has been modeled, as shown in Fig. 2. After explaining the objective function, the next step is to define the constraints. Thus, the total heat and input power in the energy hub should equal the energy hub's total heat and output power. Mathematical equations, power, and heat balance of three energy hubs, including $\mathrm{CEH}$, IEH, and $\mathrm{REH}$, are shown below:

$$
\begin{aligned}
& P_{E, \text { Net }_{1}}^{t}+P_{C H P}^{t}+P D C H_{\text {Bat }_{1}}^{t}+P_{\text {IEHtoCEH }}^{t}+P_{\text {REHtoCEH }}^{t}+P_{P V}^{t}+P_{\text {shdo }_{1}}^{t}= \\
& P_{\text {load }_{1}}^{t}+P_{\text {heater }_{1}}^{t}+P C H_{\text {Bat }_{1}}^{t}+P_{\text {CEHtoIEH }}^{t}+P_{\text {CEHtoREH }}^{t}+P_{\text {shup }_{1}}^{t} \\
& P_{E, \text { Net }_{2}}^{t}+P_{\text {wind }_{1}}^{t}+P D C H_{\text {Bat }_{2}}^{t}+P_{M T_{2}}^{t}+P_{\text {CEHtoIEH }}^{t}+P_{\text {REHtoIEH }}^{t}+P_{\text {shdo }_{2}}^{t}= \\
& P_{\text {load }_{2}}^{t}+P_{P 2 G}^{t}+P C H_{\text {Bat }_{2}}^{t}+P_{\text {IEHtoCEH }}^{t}+P_{\text {IEHtoCEH }}^{t}+P_{\text {shup }_{2}}^{t}
\end{aligned}
$$




$$
\begin{aligned}
& P_{E, N e_{3}}^{t}+P_{M T_{3}}^{t}+P_{\text {wind }}^{t}+\text { PDCH }_{\text {PHEV }}^{t}+P_{\text {CEHLREH }}^{t}+P_{\text {IEH toREH }}^{t}+P_{\text {shdo }}^{t}= \\
& P_{\text {load }_{3}}^{t}+\text { PCH }_{\text {PHEV }}^{t}+P_{\text {heater } 3}+P_{\text {REHtocEH }}^{t}+P_{\text {REHolleH }}^{t}+P_{\text {shup }}^{t} \\
& H_{\text {CHP }}^{t}+P D C H_{\text {HS }}^{t}+H_{\text {Heater }_{1}}^{t}+H_{\text {IEHtoCEHH }}^{t}+H_{\text {REHtoCEH }}^{t}+H_{\text {shdo }}^{t}= \\
& H_{\text {load }_{1}}^{t}+\mathrm{PCH}_{\mathrm{HS}}^{t}+H_{\text {CEHtoleH }}^{t}+H_{\text {CEHtoREH }}^{t}+H_{\text {shup }}^{t} \\
& H_{\text {Boiler }_{2}}^{t}+\mathrm{PDCH}_{\mathrm{HS}_{2}}^{t}+H_{\mathrm{MT}_{2}}^{t}+H_{\text {CEHtoIEH }}^{t}+H_{\text {REHtoIEH }}^{t}+H_{\text {shdo }}^{t}= \\
& H_{\text {load }_{2}}^{t}+\mathrm{PCH}_{\mathrm{HS}_{2}}^{t}+H_{\text {IEHtoCEH }}^{t}+H_{\text {IEHtoREH }}^{t}+H_{\text {shup }}^{t} \\
& H_{\text {Boiler }_{3}}^{t}+\mathrm{PDCH}_{\mathrm{HS}_{3}}^{t}+H_{\text {hedeer }_{3}}^{t}+H_{M T_{3}}^{t}+H_{\text {CEHLREH }^{t}}^{t}+H_{\text {IEHoREH }}^{t}+H_{\text {shdo }_{3}}^{t}= \\
& H_{\text {load }_{3}}^{t}+\mathrm{PCH}_{\mathrm{HS}_{3}}^{t}+H_{\mathrm{REH} \text { toCEH }}^{t}+H_{\text {REHoloHH }}^{t}+H_{\text {shup }_{3}}^{t}
\end{aligned}
$$
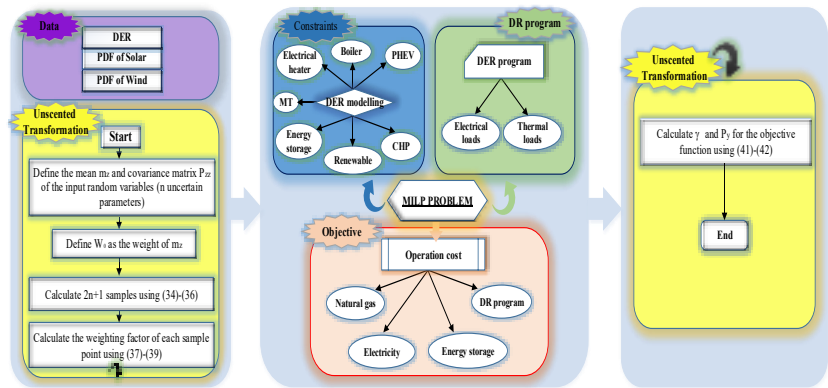

Fig. 2. Flowchart of the proposed MEH

The distributed energy resource (DER) and the PDF data of solar panels and wind turbines have been received according to the flowchart. After receiving the PDFs, the UT method is used as an estimate to solve the problem with several $2 n+1$ loads instead of employing the distribution functions. Next, energy hubs equipment models, DR program, and objective function are modeled to minimize the total system costs and increase reliability. In the last step, the mean value and covariance of $P_{y}$ are calculated based on the UT method obtained from output points.

\section{Simulation and numerical results}

This section presents the proposed linear programming problem as a linear programming problem to minimize the cost of the proposed MEH. An initial analysis has been implemented to find out the optimal route for MEH readings through the IoT protocol.

\section{A .Input data and case study}

Table 1 shows the peak price information of electricity and NG carriers, DR, and ES programs. Table 2 presents the operational information of commercial and industrial energy hub batteries. Table 3 provides PHEV battery operation information in the residential energy hub. Table 4 presents the heat storage information in the residential, industrial and commercial energy hubs. Table 5 provides CHP fuel linear operation information. The capacity of heat transfer pipelines among EHs is equal to $10 \mathrm{~kW}$ and the capacity of power transmission lines between $\mathrm{EHs}$ is equal to $20 \mathrm{~kW}$. Residential and industrial energy hubs include two microturbines that have a maximum power generation capacity of $10 \mathrm{~kW}$ and $8 \mathrm{~kW}$, respectively, and their power generation efficiency in residential and industrial hubs is $45 \%$ and $43 \%$, respectively. The maximum heat generation capacity of boilers in residential and industrial energy hubs is $15 \mathrm{~kW}$ and $25 \mathrm{~kW}$, respectively. Also, the efficiency of heat production

\begin{tabular}{|c|c|c|c|c|c|c|c|}
\hline & $(K W)$ & $P_{B u, D C H}^{\max }(K W h)$ & $E_{B d i}^{\max }(K W h)$ & $E_{B d t}^{\min }(K W h)$ & $E_{B a t}^{\text {intidal }}(K W h)$ & $\alpha_{B a t}^{\text {charge }}$ & $\alpha_{B a t}^{\text {Disch arge }}$ \\
\hline $\mathrm{CEH}$ & 5 & 5 & 45 & 5 & 25 & .8 & .8 \\
\hline IEH & 5 & 5 & 45 & 5 & 25 & .8 & .8 \\
\hline
\end{tabular}
by both boilers is $40 \%$. Figure 3 shows the daily load curves of three commercial, industrial and residential energy hubs.

Table 1

Prices of energy carriers, DR, and ES.

\begin{tabular}{ccccccccc}
\hline & \multicolumn{2}{c}{ power } & \multicolumn{2}{c}{ NG } & \multicolumn{2}{c}{ DR } & \multicolumn{2}{c}{ ES } \\
\cline { 2 - 9 } & $\begin{array}{c}\text { Off- } \\
\text { peak }\end{array}$ & $\begin{array}{c}\text { On- } \\
\text { peak }\end{array}$ & $\begin{array}{c}\text { Off- } \\
\text { peak }\end{array}$ & $\begin{array}{c}\text { On- } \\
\text { peak }\end{array}$ & $\begin{array}{c}\text { Off- } \\
\text { peak }\end{array}$ & $\begin{array}{c}\text { On- } \\
\text { peak }\end{array}$ & $\begin{array}{r}\text { Off- } \\
\text { peak }\end{array}$ & $\begin{array}{r}\text { On- } \\
\text { peak }\end{array}$ \\
\hline Price & 4 & 25 & 3 & 15 & 17 & 10 & 20 & 10 \\
\hline
\end{tabular}

Table 2

Operational information of the batteries

Table 3

Operational information of the batteries

\begin{tabular}{cccc}
\hline$P_{P H E V, C H}^{\max }(k W)$ & $P_{P H E V, D C H}^{\max }(k W)$ & $P_{P H E V}^{\max }(k W h)$ & $P_{P H E V}^{\min }(k W h)$ \\
\hline 6 & 6 & 40 & 5 \\
\hline$P_{P H E V}^{\text {initial }}(K W h)$ & $P_{P H E V}^{\text {out }}(K W h)$ & $\alpha_{P H E V}^{\text {ch arge }}$ & $\alpha_{P H E V}^{\text {Disch }}$ arge \\
\hline 20 & 10 & .85 & .85 \\
\hline
\end{tabular}

Table 4

Operational information of heat storage.

$P_{H S, C H}^{\max }(K W h) \quad P_{H S, D C H}^{\max }(K W h) \quad H_{H S}^{\max }(K W h) \quad H_{H S}^{\min }(K W h) \quad H_{H S}^{\text {intitil }}(K W h) \quad \alpha_{H S}^{c h} \alpha_{H S}^{\text {cisch arge }}$

\begin{tabular}{llllllll}
\hline CEH & 4 & 4 & 40 & 5 & 20 & .8 & .8 \\
IEH & 4 & 4 & 35 & 5 & 20 & .8 & .8 \\
REH & 4 & 4 & 35 & 3 & 20 & .8 & .8 \\
\hline
\end{tabular}

Table 5

CHP linearization operational information.

\begin{tabular}{cccccc}
\hline$j$ & $H b^{j}$ & $m_{j}$ & $i$ & $E b^{i}$ & $P i$ \\
\hline 0 & 0 & - & 0 & 3 & - \\
1 & 5 & 0.41 & 1 & 6 & .88 \\
2 & 10 & 0.85 & 2 & 9 & 1.2 \\
3 & 15 & 0.87 & 3 & 12 & 1.41 \\
& & & 4 & 15 & 1.69 \\
\hline
\end{tabular}

Table 6. Area information possible operation for CHP.

Table 6

Shows the possible operation area of CHP

\begin{tabular}{cccc}
\hline$E_{C H P, O P}^{A}$ & $E_{C H P, O P}^{B}$ & $E_{C H P, O P}^{C}$ & $E_{C H P, O P}^{D}$ \\
\hline 15 & 13 & 2 & 3.8 \\
\hline$H_{C H P, O H}^{A}$ & $H_{C H P, O H}^{B}$ & $H_{C H P, O H}^{C}$ & $H_{C H P, O H}^{D}$ \\
\hline 0 & 15 & 14 & 0 \\
\hline
\end{tabular}

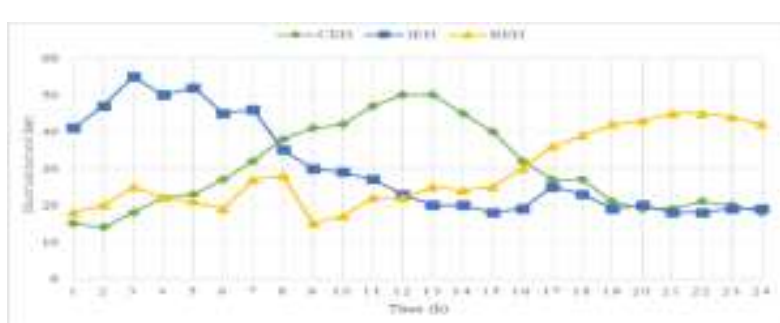

(a) Electrical loads

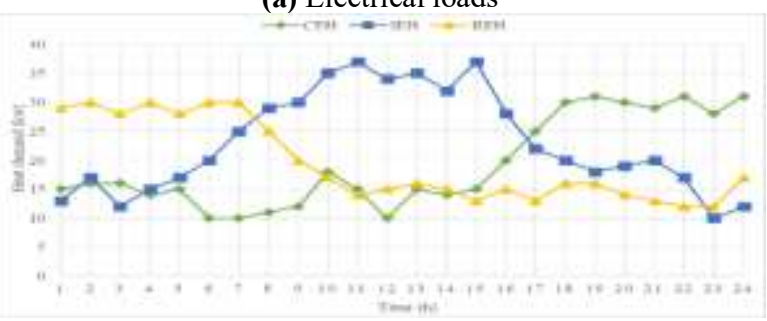

(b) Thermal loads 
Fig 3. Shows the daily curves of electrical and thermal loads of three commercial, industrial and residential energy hubs.

\section{B .Simulation result and discussion}

This section analyzes and discusses the simulation results and evaluates the performance of the proposed MEH model to minimize the cost of operation at the time horizon. The daily curve of the power output from DER on the business energy hub is shown in Fig. 4 (A). The energy carriers must be used at off-peak hours to provide electric and thermal loads in the MEH. Between 17:00 and 24:00 pm, CEH natural gas demand is at its peak. Therefore, the CHP electricity and heating demand decrease from 17:00 to 24:00 pm. At its peak hour, the demand for NG and electricity in IEH is 07:00 am to 4:00 pm, and 01:00 am to 08:00 am... For this purpose, the boiler has reduced its heat consumption demand from 06:00 to 16:00 due to the high rate of gas prices so that it does not produce any heat from 07:00 to 16:00 and starts again from 17:00 to 24:00 to generate its heat. From 06:00 to $16: 00$, the P2G converter also provides heat loads and compensates its generation at this time. From 01:00 to 06:00, no electricity has been generated because of the high electricity tariffs. In addition, from 08:00 to 16:00, there is reduced production of MT because of high gas prices. From 01: 00 to 08: 00, given the high tariffs, MT is used to meet the demands of electric charges. In Fig. $\mathbf{4 b}$, the production capacity of WT1 is represented for 24 hours.

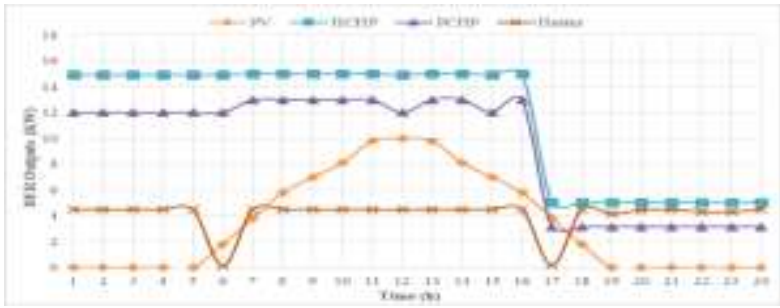

a. Power output from DER on commercial energy hub

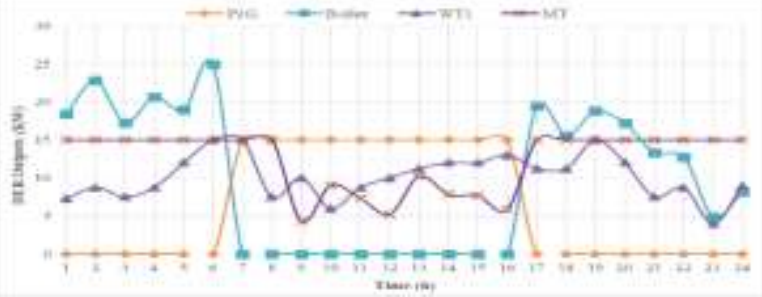

b. Power output from DER on industrial energy hub

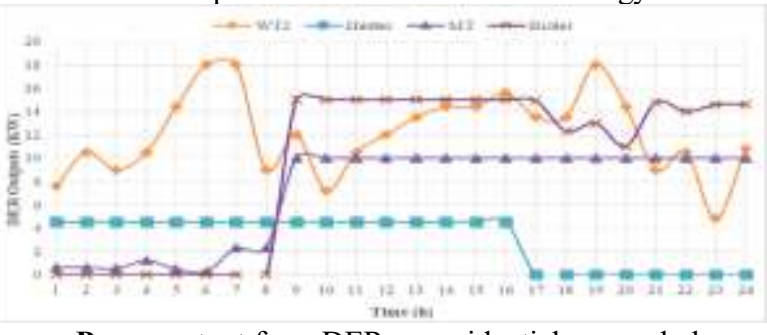

c. Power output from DER on residential energy hub

Fig 4. MEH's curve of output power in 24 hours

As shown in Fig. 4c, in the residential energy hub, the demand for NG and electricity is from 01: 00 to 08:00 in the afternoon and 17: 00 to 24:00 at the peak hours, respectively. Due to high electricity tariffs, the heater decreases the electricity demand from 17:00 to 24:00. However, MT has reduced its generation from 01:00 to 08:00 due to the high price of NG. MT starts generating electricity from 08:00 to 24:00 to supply electrical charges. Due to the high NG tariff, from 01:00 to 08:00, the boiler stops its production. Figure 5 and figure 6 show the daily charge and discharge curves and the State Of Charge of MEH energy reserves, respectively.

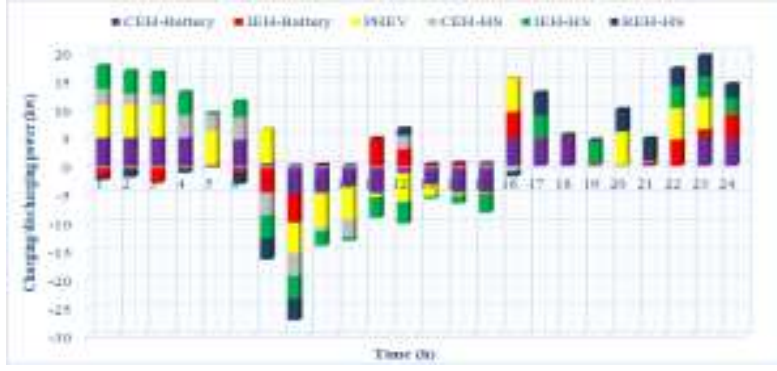

Fig. 5. Charge and discharge curve of MEH energy reserves

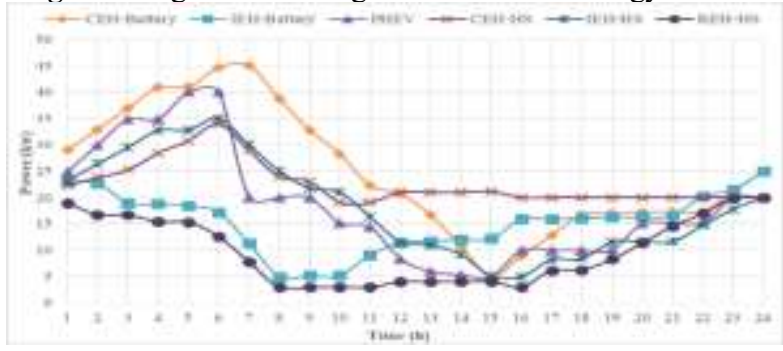

Fig. 6. Daily SOC curve of MEH energy reserves

When the hubs' electricity and natural gas demand is off-peak, the energy reserves are charged during these hours during the peak hours of consumption. When the demand for energy consumption for feeding loads increases, the energy reserves are depleted during these hours. While energy demand decreases, energy reserves are recharged. Electricity consumption demand in $\mathrm{CEH}$ is at its peak from 08:00 to 15:00, so the price of electricity at this hour is the highest. Therefore, the batteries contribute to network reliability by releasing energy and storing electrical energy from 01:00 to 07:00 and from 16:00 to 24:00. At IEH, demand for NG peaks from 07:00 to 4:00 pm. During these hours, with the release of HS, thermal loads are fed. From 01:00 to 06:00 and 17:00 to 24:00 that the demand and price of NG are low, HS is recharged, which is also true for other energy reserves. B)

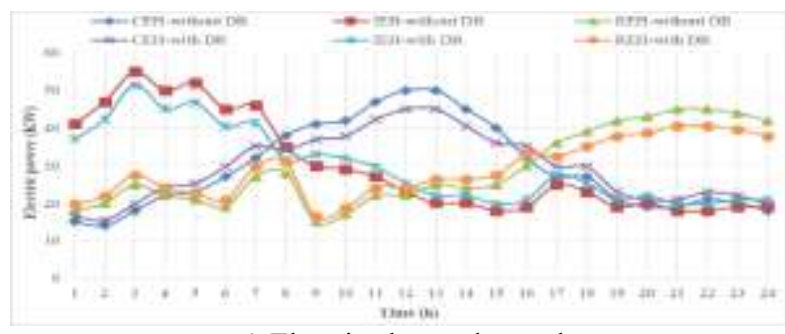

a) Electric charge demand

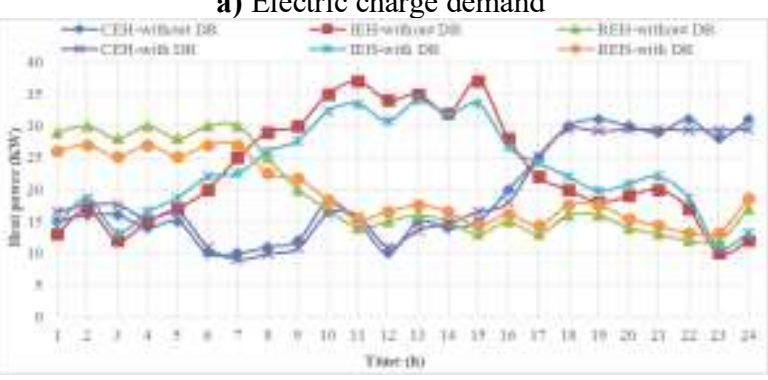


b) Demand for thermal load

Fig 7. Daily MEH curves before and after DR use

According to Fig. 7 (a), MEH electric charge demands can be reduced during peak hours by using the carrier. The demand for electricity consumption in $\mathrm{REH}, \mathrm{IEH}$, and $\mathrm{CEH}$ is in peak demand from 17: 00 to 24:00, from 01:00 to 08: 00, and from 08: 00 to 15: 00 , respectively. The electric charge changes from on-peak to off-peak with $\mathrm{DR}$, and transmission occurs for thermal loads, as for electric charges. In the IEH, the NG's demand is at on-peak from 7:00 am to 4:00 pm. So the heat loads of this hub at this time change from on-peak to off-peak. This section examines other MEH issues. The proposed MEH offers a new management framework for the simultaneous operation of different energy carriers. Besides, optimal planning and distribution of energy among multi-energy hubs contribute to supplying electrical and thermal loads. When one of the hubs is calculated at a high tariff, other energy hubs can help by exchanging thermal and electrical energy at a lower price, improving efficiency and system reliability. Moreover, the proposed MEH comprises many equipment types, including energy resources, storage devices, and CHPs that supply electrical and thermal charges. For example, when the price of natural gas is high, the required heat load is provided by an electric heater. The system's power is supplied via MT when electricity is high-priced. WTs and PVs are two worldwide solutions to generating low-carbon electricity. Fig. 8 shows the purchased electricity and gas curve from the network. In Fig. 8, MEH reduces the network's electricity and gas when charged at high tariffs. Table 7 shows the operation costs with and without uncertainty. Regarding the uncertainty of renewable resources and the interdependence between wind turbines, the operation cost of the entire system has been reduced. Fig. 9. The curve shows the normal distribution function.

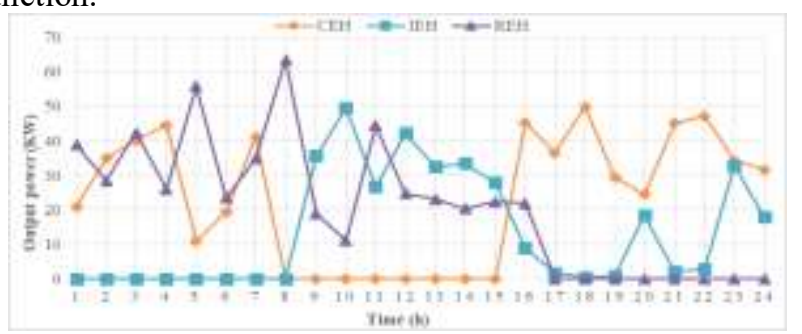

a) Power

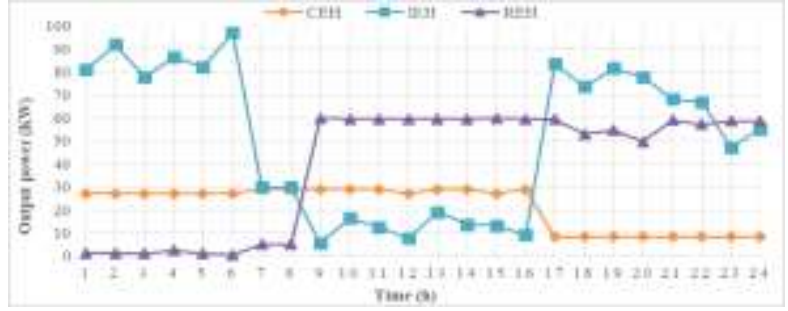

b) Gas

Fig 8. The daily curve of electricity and the natural gas amount purchased from the network

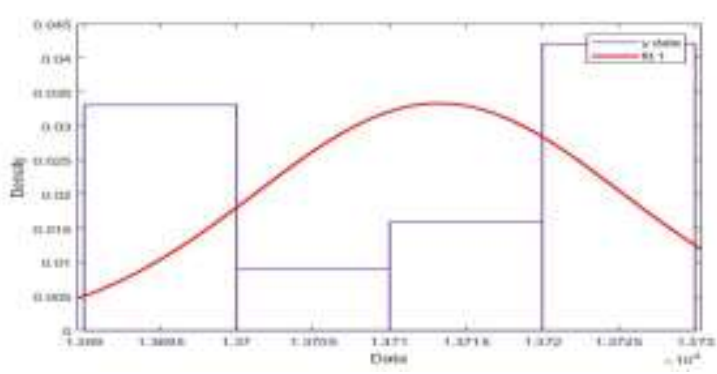

Fig 9. Probability distribution function

Table 7: The operation costs

\begin{tabular}{ccc}
\hline $\operatorname{cost}(\$)$ & $\begin{array}{c}\text { Uncertainty based on } \\
\text { base scenario }\end{array}$ & $\begin{array}{c}\text { Uncertainty based } \\
\text { on UT }\end{array}$ \\
\hline operation cost & $\mathbf{1 3 7 3 2 / 7 5 0}$ & $\mathbf{1 3 7 0 9 / 1 5 2 3 5}$ \\
\hline
\end{tabular}

\section{Conclusion}

This paper proposed an IoT-based model to study the connection among different energy carriers in interconnected residential, commercial and industrial energy hubs. Each EH consists of various equipment, including a CHP unit, clean and renewable resources, PHEV, boilers, and the HS unit. A UT-based stochastic framework has been introduced for recording renewable resource uncertainty. The simulation results show that the exchange of power and heat between energy hubs reduces the dependence on electricity and natural and the overall network expenditure. Furthermore, when the energy demand is off-peak, energy storage can significantly affect the supply of required loads during high peak hours. Finally, the DR program and promoting optimal consumption will lead to less network operating costs and adjust the load demand curve, influencing energy markets significantly. In the future works, authors would assess developing fully distributed framework and the cyber security concerns.

\section{References}

[1]A. E. O. 2019, “Annual Energy Outlook 2019 with projections to 2050," Annu. Energy Outlook 2019 with Proj. to 2050, vol. 44, no. 8, pp. 1-64, 2019.

[2] Zhiguo Zhao;Liangjie Zhou;Yugong Luo;Keqiang Li, "Emergency Steering Evasion Assistance Control Based on Driving Behavior Analysis", IEEE Transactions on Intelligent Transportation Systems, Year: 2019 |,Volume: 20, Issue: 2.

[3] J. Chen;M.Weiszer;P. Stewart;M. Shabani, "Toward a More Realistic, Cost-Effective, and Greener Ground Movement Through Active Routing_-Part I: Optimal Speed Profile Generation", IEEE Trans. Intelligent Trans. Systems, 2016, vol. 17, no.5.

[4] M. I. Khalil, N. Z. Jhanjhi, M. Humayun, S. K. Sivanesan, M. Masud, and M. S. Hossain, "Hybrid smart grid with sustainable energy efficient resources for smart cities," Sustain. Energy Technol. Assessments, vol. 46, p. 101211, Aug. 2021.

[5] Yidong Li;Li Zhang;Zhuo Lv;Wei Wang, "Detecting Anomalies in Intelligent Vehicle Charging and Station Power Supply Systems With Multi-Head Attention Models", IEEE Transactions on Intelligent Transportation Systems, Year: 2021

[6] P. Najafi and S. Talebi, "Using real options model based on Monte-Carlo Least-Squares for economic appraisal of flexibility for electricity generation with VVER-1000 in developing countries," Sustain. Energy Technol. Assessments, vol. 47, p. 101508, Oct. 2021.

[7] M. R. Yaghoubi-Nia, H. Hashemi-Dezaki, and A. Halvaei Niasar, "Optimal stochastic scenario-based allocation of smart grids' renewable and non-renewable distributed generation units and 
protective devices," Sustain. Energy Technol. Assessments, vol. 44, p. 101033, Apr. 2021.

[8]F.de O.Antonio,"Wave energy utilization: A review of the technologies," Renew. Sustain. energy Rev., vol. 14, no. 3, pp. 899918, 2010

[9] S. Hajiaghasi, A. Salemnia, and M. Hamzeh, "Hybrid energy storage system for microgrids applications: A review," J. Energy Storage, vol. 21, pp. 543-570, Feb. 2019.

[10] M. S. Javadi, A. Anvari-Moghaddam, and J. M. Guerrero, "Optimal scheduling of a multi-carrier energy hub supplemented by battery energy storage systems," in 2017 IEEE International Conference on Environment and Electrical Engineering, 2017, pp. $1-6$.

[11] M. Majidi, ... B. M.-I.-A. T., and undefined 2019, "Optimal robust operation of combined heat and power systems with demand response programs," Elsevier, vol. 149, pp. 1359-1369, 2018.

[12] Z. Zeng, T. Ding, Y. Xu, ... Y. Y.-I. T. on, and undefined 2019, "Reliability evaluation for integrated power-gas systems with power-to-gas and gas storages," ieeexplore.ieee.org, Accessed: Jul. $14,2021$.

[13] X. Zhang, M. S.-... on S. Grid, and undefined 2015, "Optimal expansion planning of energy hub with multiple energy infrastructures," ieeexplore.ieee.org.

[14] X. Zhang, L. Che, M. Shahidehpour, A. S. Alabdulwahab, and A. Abusorrah, "Reliability-Based Optimal Planning of Electricity and Natural Gas Interconnections for Multiple Energy Hubs," IEEE Trans. Smart Grid, vol. 8, no. 4, pp. 1658-1667, Jul. 2017.

[15] A. Najafi, H. Falaghi, J. Contreras, and M. Ramezani, "A Stochastic Bilevel Model for the Energy Hub Manager Problem," IEEE Trans. Smart Grid, vol. 8, no. 5, pp. 2394-2404, Sep. 2017.

[16]M. Mostafavi Sani, A. Noorpoor, and M. Shafie-Pour Motlagh, "Optimal model development of energy hub to supply water, heating and electrical demands of a cement factory," Energy, vol. 177, pp. 574-592, Jun. 2019.

[17] J. Salehi, A. Namvar, and F. S. Gazijahani, "Scenario-based CoOptimization of neighboring multi carrier smart buildings under demand response exchange," J. Clean. Prod., vol. 235, pp. 14831498, Oct. 2019.

[18] Y. Xu, T. DIng, M. Qu, and P. Du, "Adaptive Dynamic Programming for Gas-Power Network Constrained Unit Commitment to Accommodate Renewable Energy with CombinedCycle Units," IEEE Trans. Sustain. Energy, vol. 11, no. 3, pp. 20282039, Jul. 2020.

[19] M. Daneshvar, S. Asadi, and B. Mohammadi-Ivatloo, "Grid Modernization - Future Energy Network Infrastructure," 2021.

[20] M. H. Amirioun, F. Aminifar, and M. Shahidehpour, "Resilience-promoting proactive scheduling against hurricanes in multiple energy carrier microgrids," IEEE Trans. Power Syst., vol. 34, no. 3, pp. 2160-2168, May 2019.

[21] A. G. Olabi and M. A. Abdelkareem, "Energy storage systems towards 2050," Energy, vol. 219, p. 119634, Mar. 2021.

[22] S. E. Razavi, M. S. Javadi, and A. Esmaeel Nezhad, "Mixedinteger nonlinear programming framework for combined heat and power units with nonconvex feasible operating region: Feasibility, optimality, and flexibility evaluation," Int. Trans. Electr. Energy Syst., vol. 29, no. 3, pp. 1-18, 2019.

[23] X. Lu, Z. Liu, L. Ma, L. Wang, K. Zhou, and S. Yang, “A robust optimization approach for coordinated operation of multiple energy hubs," Energy, vol. 197, p. 117171, Apr. 2020.

[24]R. Mehta, P.Verma,D.rinivasan, and J. Yang,"Double-layered intelligent energy management for optimal integration of plug-in electric vehicles into distribution systems," Appl. Energy, vol. 233234, pp. 146-155, Jan. 2019,

[25] I. Yahyaoui, A. Yahyaoui, M. Chaabene, and F. Tadeo, "Energy management for a stand-alone photovoltaic-wind system suitable for rural electrification," Sustain. Cities Soc., vol. 25, pp. 90-101, Aug. 2016.
[26]G. Tina, M. Rosa-Clot, P. Rosa-Clot, P. S.- Energy, and undefined 2012, "Optical and thermal behavior of submerged photovoltaic solar panel: SP2,” Elsevier, Accessed: Aug. 04, 2021. [27]J. Hetzer, C. Y. David, and K. Bhattarai, "An economic dispatch model incorporating wind power," IEEE Trans. energy Convers., vol. 23, no. 2, pp. 603-611, 2008.

[28]M. Kefayat, A. Lashkar Ara, and S. A. Nabavi Niaki, "A hybrid of ant colony optimization and artificial bee colony algorithm for probabilistic optimal placement and sizing of distributed energy resources," Energy Convers. Manag., vol. 92, pp. 149-161, Mar. 2015.

[29]X. Lu et al., "A robust optimization approach for coordinated operation of multiple energy hubs," Elsevier, Accessed: Jul. 23, 2021.

[30] A Kavousi-Fard, T Niknam, M Fotuhi-Firuzabad, "Stochastic Reconfiguration and Optimal Coordination of V2G Plug-in Electric Vehicles Considering Correlated Wind Power Generation", IEEE Transactions on Sustainable Energy 6 (3), 822-830, 2015. 